\title{
Hot melt extrusion method for preparation of ibuprofen/sucroester WE15 solid dispersions: evaluation and stability assessment
}

\author{
Laila H. Emara*, Fatma M. Abdelfattah, Nesrin F. Taha \\ Industrial Pharmacy Laboratory, Medical and Pharmaceutical Chemistry Department, Division of Pharmaceutical Industries, National Research Centre \\ (Affiliation ID: 10014618), 33 EL Bohouth st. (former EL Tahrir st.), Dokki, Giza, Egypt.
}

\begin{tabular}{|c|c|}
\hline ARTICLE INFO & ABSTRACT \\
\hline Article history: & \multirow{9}{*}{$\begin{array}{l}\text { Low melting points Sucroesters (SEs) are used in hot-melt extrusion technology (HME). However, there are few } \\
\text { literatures studying the effect of SEs on drug release and their storage stability. In this study, SE }{ }^{\circledR} \text { WE15 was } \\
\text { proposed to prepare sustained-release solid dispersions with Iburpofen (IBU), containing } 60 \& 30 \% \mathrm{w} / \mathrm{w} \text {, by } \\
\text { HME, fusion method and compared to physical mixtures. The fresh and stored samples were evaluated by a } \\
\text { well-established release rate study (USP Apparatus IV), DSC and XRD. Results revealed that HME technique } \\
\text { succeeded to produce sustained-release patterns for IBU. Stored samples }\left(6 \text { months at } 40{ }^{\circ} \mathrm{C} / 75 \% \mathrm{RH}\right) \mathrm{were} \\
\text { unstable and showed gradual decrease in IBU release rate for both IBU loadings. HME formula }(60 \% \mathrm{w} / \mathrm{w} \mathrm{IBU}) \\
\text { showed an increase in the amount of drug released. Long term stability, one year at room temperature, showed a } \\
\text { marked increase in IBU release rate for both drug loadings. Only HME containing } 30 \% \mathrm{w} / \mathrm{w} \text { IBU gave stable } \\
\text { form among others. DSC and XRD suggested that increase of SE content led to almost complete IBU dissolved } \\
\text { in this carrier, and considerable decrease in IBU release rate. This has been proven by DSC and XRD data } \\
\text { analysis for IBU and SE (enthalpy and counts). }\end{array}$} \\
\hline Received on: 15/01/2017 & \\
\hline Accepted on: 11/04/2017 & \\
\hline Available online: $30 / 08 / 2017$ & \\
\hline Key words: & \\
\hline Solid Dispersion; Hot Melt & \\
\hline Extrusion; Sucroester ${ }^{\circledR}$ & \\
\hline WE15; Stability; Ibuprofen. & \\
\hline & \\
\hline
\end{tabular}

\section{INTRODUCTION}

Solid dispersions (SDs) technique has attracted substantial interest as an efficient mean of improving the dissolution rate as well as the bioavailability of a wide range of poorly aqueous soluble drugs (Hasnain and Nayak, 2012). Also, SDs can be used to sustain the drug release by selecting an appropriate polymer (Craig, 2002; Serajuddin, 1999). The two major processes of preparing SDs are melting (fusion) and solvent evaporation methods (Van den Mooter, 2006; Vilhelmsen et al., 2005; Won et al., 2005). Other various approaches include co-evaporation (Hong et al., 2011), hot spin mixing

\footnotetext{
* Corresponding Author

Laila H. Emara, Industrial Pharmacy Laboratory, Medical and

Pharmaceutical Chemistry Department, Division of Pharmaceutical Industries, National Research Centre (Affiliation ID: 10014618), 33 EL Bohouth st. (former EL Tahrir st.), Dokki, Giza, Egypt.

Email:lhhemara@yahoo.com
}

(Dittgen et al., 1995), roll-mixing or co-milling (Breitenbach, 2002), freeze-drying (Sekikawa et al., 1983), spray drying (Caron et al., 2011), and supercritical fluid processing (SFP) (Gong et al., 2005). In the 1980s, hot melt extrusion (HME) was used for the first time in the formulation of pharmaceuticals (Stankovic et al., 2013). The advantages of HME over the conventional approaches are: economical process, short production time, continuous operation with few processing steps and ease of scaling-up (Maniruzzaman et al., 2012). During HME of pharmaceutical dosage forms, a blend of active ingredient, thermoplastic polymeric carrier, and other processing aids (plasticizers and antioxidants) is heated and softened inside the extruder and then pressurized through a die into granules, cylinders, or films (Zhang and McGinity, 2000). Sucrose esters (SEs) are applied in HME technology as promising carriers, because of their low melting points and their surfactant properties, but the information available on these carriers is not sufficient and further investigations are needed (Szüts et al., 2008). 
Ibuprofen (IBU) is widely used as a safe non-steroidal anti-inflammatory drug (NSAID) for the treatment of pain, inflammation, arthritis and dysmenorrhea (Higgins et al., 2001). IBU has a short elimination half-life (2-3 hours), thus frequent dosing is necessary to maintain therapeutic plasma levels (Higgins et al., 2001). Therefore, preparation of sustained-release formulations of IBU will decrease the frequency of administration; reduce the exposure time of the gastrointestinal tract (GIT) to drug; maintain the required therapeutic plasma level, decrease side effects, thus, increase the patient's compliance (Higgins et al., 2001).

It is well known that polymeric carriers used in HME typically require a plasticizer in order to reduce the glass transition temperature ( $\mathrm{Tg}$ ) and viscosity of the polymers during pharmaceutical HME (Aharoni, 1998). The plasticizing effect can be attributed to the increase of free volume, the decrease of friction between polymer chains and the consequent improvement of chain mobility of polymer, resulting in reducing the drug and polymeric carrier degradation and improve the stability profile of the active compound (Aharoni, 1998). IBU, a low melting point drug (78 ${ }^{\circ} \mathrm{C}$ ), with a known plasticizing effect, and higher IBU loading led to subsequent increase in its plasticizing effect as reported previously with different polymers such as Kollidon ${ }^{\circledR}$ SR (De Brabander et al., 2002; Kidokoro et al., 2001; Özgüney et al., 2009). Therefore, IBU is considered a good candidate for HME technologies.

Previous literature had discussed various preparations of IBU/ SDs for improving its dissolution using different carriers (Dabbagh and Taghipour, 2007; Esnaashari et al., 2005; Islam et al., 2010; Newa et al., 2007; Newa et al., 2008a; Newa et al., 2008b; Newa et al., 2008c; Park et al., 2009; Xu et al., 2007). SDs prepared by fusion method was used to enhance the solubility, dissolution rate and absorption of IBU using PEG 6000 (Gawai et al., 2013), mixture of tween 80 \& span 80 (Shahrin and Huq, 2012) and polyethylene glycol (PEG) 8000 (Ofokansi et al., 2016). However, very limited reports are available up till now for preparation of sustained-release SDs of IBU using HME technique. Özgüney et al. (2009) developed IBU/SDs using Kollidon ${ }^{\circledR}$ SR. Other studies prepared sustained-release extrudates of IBU with ethyl cellulose and xanthan gum (De Brabander et al., 2003; Verhoeven et al., 2006). Kidokoro et al., 2001 developed IBU/Eudragit RS PO tablets prepared by hot melt processing. Also IBU was used with combination of microcrystalline waxes and starch derivatives to prepare SDs (De Brabander et al., 2000).

Our previous work was done to prepare IBU/HME pellets using SE®WE15 as an extrudable carrier (Emara et al., 2014). The prepared pellets were in vitro evaluated, for the first time in literature, by flow through cell dissolution tester (FTC, USP Apparatus IV) using different operational conditions to select the most appropriate method for proper discrimination between formulations containing different IBU loading ratios. That study investigated the effect of different cell sizes (large and small), flow conditions (turbulent and laminar) and pellets loading into the FTC (Emara et al., 2014). The FTC method reported the optimum conditions for drug release from different formulations, solved the problems of unreliable release data due to spreading of pellets to undefined sites of the cell and thereby, eliminated the resulting errors in the release rate data and thus, achieved the highest reproducibility of results (Emara et al., 2014). This FTC design was chosen as an alternative to the conventional USP I \& II apparatuses, where in a previous study using a modified paddle method, no differences in drug release profiles between the $60 \%$ \& $40 \%$ w/w IBU loading was noticed (De Brabander et al., 2000). Therefore, for in vitro dissolution testing, validation of the method selected is very critical to monitor any change in product performance which could affect its bioavailability.

Although SEs are widely used in HME technique, yet, no published data are available on the applicability of SEs prepared by HME on the dissolution behavior and physical stability of drug /carrier system after storage under different conditions.

The aim of the present study was the development of sustained-release IBU/ SDs using HME technique with $\mathrm{SE}^{\circledR}$ WE15 as an extrudable carrier. Moreover, SDs prepared by the traditional fusion method (FM) as well as their respective physical mixtures (PM) were also prepared for comparisons. The most important target was to test the stability of the proposed SDs, to select a promising formula for in vivo testing. The system stability was done by studying the IBU content by HPLC, release rate by a properly designed FTC, DSC as well as XRD.

\section{MATERIALS AND METHODS}

\section{Materials}

Pure Ibuprofen (IBU) was kindly donated from Sigma pharma, Cairo, Egypt. Sucroester ${ }^{\circledR}$ WE15 $\left(\right.$ SE $^{\circledR}$ WE15)(HLB=15) was obtained from Gattefose S.A., France. Sodium hydroxide pellets and potassium dihydrogen orthophosphate were purchased from Laboratory Rasayan, India. HPLC grade acetonitrile and Sodium dihydrogen phosphate (NaH2PO4) were purchased from Merck, (Germany). Milli-Q purified water (Millipore Corp., Billerica, MA, USA) was used to prepare the dissolution medium.

\section{Methods}

\section{Preparation of solid dispersions by hot melt extrusion}

SDs of IBU/ SE®WE15 was processed using HME with two different IBU loading ratios, i.e. $60 \%$ and $30 \%$ w/w for HME1 and HME-2, respectively. Extrusion was performed using 1/4 inch single screw extruder with a single rod die (Randcastle Microtruder RC-025, Randcastle Extrusion Systems, Inc., USA). The four zones of the extruder were heated to the required temperatures ranges from $55-65^{\circ} \mathrm{C}$ and screw rotation was set at $30 \mathrm{rpm}$. The extrusion conditions and steps required to form the final product was previously discussed (Emara et al., 2014) with slight modification. The prepared hot melt extrudates were cut manually into pellets with the following dimensions: length equals to $1 \pm 0.1 \mathrm{~mm}$ and width equals to $0.6 \pm 0.1 \mathrm{~mm}$. Equivalent dose of IBU in each formula was $400 \mathrm{mg}$. 


\section{Preparation of solid dispersions by fusion method}

SDs of IBU/ SE ${ }^{\circledR}$ WE15 was prepared by melting the required amount of drug and carrier for each formula in a hot plate on a water bath maintained at the specified temperature $\left(65^{\circ} \mathrm{C}\right)$ for 10 minutes till complete melting. The fused mixture was cooled at room temperature, kept in vacuum oven overnight to solidify. The solidified mass was ground in a mortar, sieved to obtain particle size ranges of $850 \mu \mathrm{m}-710 \mu \mathrm{m}$ and $<450 \mu \mathrm{m}$. The fusion mixtures were coded as FM-1 (60/40\%w/w) and FM-2 (30/70 $\% \mathrm{w} / \mathrm{w}$ ) for two different ratios of IBU / SE ${ }^{\circledR} \mathrm{WE} 15$, respectively.

\section{Preparation of physical mixtures}

Physical mixtures (PM-1 \& PM-2) of IBU and SE®WE15 in the same weight ratios as the SDs were prepared by thoroughly mixing the appropriate amount of IBU and carrier in a mortar by trituration for 15 minutes, and then sieving through a 60 mesh sieve. Granules of $850 \mu \mathrm{m}$ to $710 \mu \mathrm{m}$ were then prepared by dry granulation.

\section{Determination of percent drug content by HPLC}

An accurately weighed amount of PM and SDs, each equivalent to the amount of IBU in each formula were dissolved in acetinitrile, volume was adjusted to $25 \mathrm{~mL}$, vortexed and filtered (Millex, $0.45 \mathrm{um}$ ). The filtrate was further diluted with mobile phase consisting of a mixture of acetonitrile/phosphate buffer (60:40, v/v, $\mathrm{pH} 7.0)$ and analyzed for drug content by an HPLC/UV method as described previously (Battu and Reddy, 2009). The HPLC apparatus consists of Waters 600 E Multi Solvent Delivery System Controller equipped with Rheodyne injector P/N 7725i, and Waters 2487 Dual $\lambda$ Absorbance Detector coupled to Millennium 32 computer program. Chromatographic separation was achieved using a Symmetry C18 column $(5 \mu \mathrm{m}$, 3.9X150, Waters Assoc., USA) protected by a guard pack precolumn module with Symmetry C18, $5 \mu \mathrm{m}$ inserts (Waters Assoc., USA). The flow rate was adjusted to $0.8 \mathrm{~mL} / \mathrm{min}$ with UV detection at $260 \mathrm{~nm}$ and the column was kept at room temperature. The adopted method was selective and sensitive with LOD and LOQ equal to $10 \mathrm{ng} / \mathrm{mL}$ and $25 \mathrm{ng} / \mathrm{mL}$, respectively. Each formulation was tested in triplicates.

\section{In vitro drug release studies}

In vitro drug release studies of IBU powder, PM and the prepared SDs were carried-out as described previously in details (Emara et al., 2014); using the closed loop setup of flow through cell (FTC) dissolution apparatus (USP IV, a Dissotest CE-6 equipped with a CY 7-50 piston pump, Sotax, Switzerland) in phosphate buffer $\mathrm{pH}$ 7.2. The dissolution studies were done in triplicate and the mean value was calculated.

The FTC design selected to perform the dissolution studies had proven its efficacy to achieve the optimum conditions for IBU release from the proposed formulations; also it was able to discriminate between formulations containing different IBU loading ratios (Emara et al., 2014).

\section{Stability Studies}

Stability studies were conducted as stated by ICH guidelines, 2003 on the prepared SDs along with PM to assess their stability with respect to DSC, XRD, chemical stability by HPLC and drug release characteristics. The prepared formulae were placed in a tightly closed glass container and subjected to accelerated stability study using thermostatically controlled oven adjusted at $40{ }^{\circ} \mathrm{C} \pm 0.5{ }^{\circ} \mathrm{C}$ with $\mathrm{RH}$ of $75 \%$ (maintained using a saturated solution of $\mathrm{NaCl}$ ) for 6 months as well as storage at room temperature ranged from $18{ }^{\circ} \mathrm{C}$ to $33^{\circ} \mathrm{C}$ for 12 months.

\section{Differential Scanning Calorimetry (DSC)}

Thermal behavior of the powdered IBU, SE ${ }^{\circledR} \mathrm{WE} 15$, PM and the prepared SDs were examined by differential scanning calorimetry (DSC-50, Shimadzu, Japan) to investigate the state of drug and carrier in the different tested samples and to assess incompatibility if any in the prepared samples. DSC analysis was performed for fresh samples as well as samples stored at different conditions. The thermograms were performed using an automatic thermal analyzer (DSC-50). Accurately weighed samples $(5 \mathrm{mg})$ were placed directly into pierced aluminum pans and the thermal analysis was carried - out using heating ramp from 25 to $300{ }^{\circ} \mathrm{C}$ at $10{ }^{\circ} \mathrm{C} / \mathrm{min}$ scale up rate. A nitrogen purge $(20 \mathrm{~mL} / \mathrm{min})$ was maintained throughout the run.

\section{X-ray Diffraction (XRD)}

X-ray diffraction patterns of the fresh and stored SDs, compared with pure drug and carrier were recorded by using Empyrean diffractometer. Samples were irradiated with monochromatized $\mathrm{Cu} \mathrm{K} \alpha$ radiation, and analyzed between $2 \theta$ of $3^{\circ}$ and $80^{\circ}$, with step size $0.026^{\circ}$. The voltages, current and time per step were $45 \mathrm{kV}, 30 \mathrm{~mA}$, and $18.87 \mathrm{~s}$, respectively.

\section{Statistical Analysis}

In vitro drug release of stored samples was compared with fresh samples by employing the similarity factor $\left(f_{2}\right)$ as proposed by Moore and Flanner, 1996, according to the following equation:

$$
f_{2}=50 \bullet \log \left\{\left[1+(1 / n) \Sigma_{t=1}{ }^{n}\left(R_{t}-T_{t}\right)^{2}\right]^{-0.5} \bullet 100\right\}
$$

Where, $n$ is number of time points, $R_{t}$ and $T_{t}$ are cumulative percentage releases at the selected $\mathrm{n}$ time point of the reference and the test product, respectively.

The similarity factor $\left(f_{2}\right)$ is a measure of the similarity between two dissolution curves and its value ranges from 0 and 100. FDA suggests that two dissolution profiles are considered similar if the similarity factor $f_{2}$ is between 50 and 100 (US-FDA, 1997).

\section{RESULTS AND DISCUSSION}

\section{Drug Content}

The percentages drug content of various IBU/ SDs as well as their corresponding PM were within the range of $97.76 \pm$ 
$8.08 \%$ to $107.94 \pm 7.64 \%$ which complied with the accepted pharmacopoeial limits (British Pharmacopoeia, 2007).

\section{In vitro release study for fresh samples}

Our previous study on IBU/SE ${ }^{\circledR} \mathrm{WE} 15$ sustained-release pellets using HME technique containing different drug concentrations were evaluated using specific operational conditions of the FTC dissolution apparatus (Emara et al., 2014). These specific features of the FTC were selected in order to develop a sensitive in vitro method to precisely discriminate between different formulations, ensure high reproducible in vitro results and to detect even minor differences which might occur after storage (Emara et al., 2014). SDs of different particle sizes prepared by fusion method showed the same release rate results. Therefore, the particle size range of 850 - 710 um was selected for further studies.

SDs of IBU was previously prepared by different techniques and compared with its physical mixtures for better understanding of the effect of different methods on the physicochemical characteristics of the drug. IBU/SDs were previously prepared by the solvent and fusion-solvent methods using different carriers and compared with the physical mixtures (Dabbagh and Taghipour, 2007). In vitro dissolution results showed that SDs containing Eudragit or HPMC resulted in retardation of the dissolution of IBU, while SDs containing PEG gave faster dissolution rates than the physical mixtures (Dabbagh and Taghipour, 2007). Also, IBU/SDs was prepared by melt dispersion technique using macrogol 4000 and 6000 as carriers (Al Masum et al., 2012). The results showed that the prepared SDs enhanced the dissolution of IBU relative to physical mixtures.

Figure 1 showed the release profiles of different preparations of IBU/ SE ${ }^{\circledR} \mathrm{WE} 15$ SDs (containing $60 \%$ and $30 \%$ w/w IBU) prepared by HME \& FM, the prepared PM and comparing the results with pure IBU powder.

Aggregation and agglomeration of PM were observed during dissolution study. The results showed that the physical mixtures (i.e. PM-1 \& PM-2) and SDs prepared by fusion method (i.e. FM-1 \& FM-2) did not cause any pronounced change in the amount of IBU released (Figures $1 \mathrm{~A} \& \mathrm{~B}$ ) compared to the observed sustained-release effect detected with hot melt extrudates (i.e. HME-1 \& HME-2). In case of $60 \%$ w/w IBU, PM-1 and FM1 showed the same release profiles, while HME-1 significantly slowed the release rate (Figure 1A \& Table 1).

Figure $1 \mathrm{~B} \&$ Table 1 also showed that both PM-2 and FM-2 containing 30\% w/w IBU, gave comparable release patterns with pure drug, while HME-2 showed the slowest release rate. These results clearly identify the advantages of HME technique over the other conventional methods as it provides uniform and intimate dispersion and/ or mixing of all ingredients by the high shear extruding forces. Thereafter, SDs prepared by different methods can have differences in product release properties, which might affect its performance based on a case by case study.

After 8 hours release study, $64.65 \%$ and $47.09 \%$ of IBU were released from HME-1 (60\% IBU) and HME-2 (30\% IBU), respectively (Table 1). This might be due to possible solid-state interactions and the higher content of $\mathrm{SE}^{\circledR}$ WE15 in HME-2 sample, resulting in more intimate distribution and entrapment of IBU within the SE structure. This result could be used to tailor the required release profile by increasing the percentage of SEs in the formula.
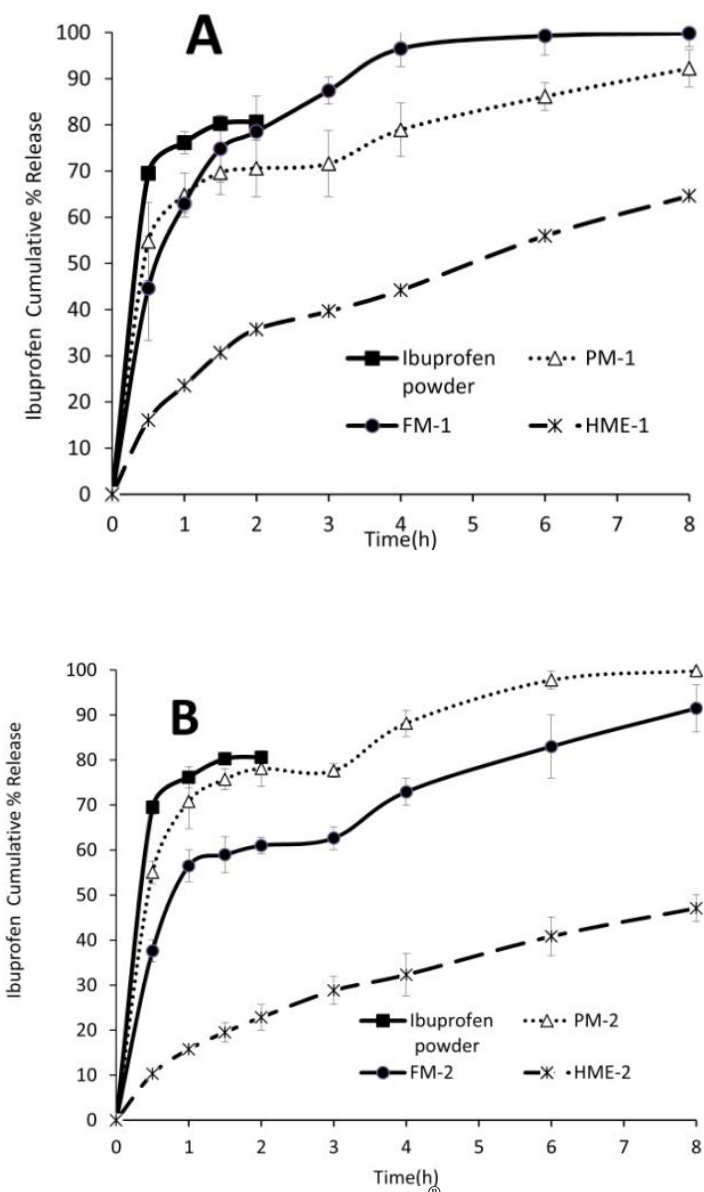

Fig. 1: Release profiles of IBU/Sucroester ${ }^{\oplus}$ WE15 from SDs prepared by fusion method (FM) and hot-melt extrusion (HME) with their respective physical mixture (PM) at: (A) 60\% drug loading; (B) 30\% drug loading. (Mean $\pm \mathrm{SD}, n=3$ ).

While, SE ${ }^{\circledR}$ WE15 succeeded to sustain the IBU release rate up to 8 hours from hot melt extrudates, however, it was used previously to enhance the release of poorly soluble compounds: 17-Estradiol (Hülsmann et al., 2000) and Nifedipine (Badr, 2006). Szüts et al., 2008 used the melt technology (i.e. fusion method) to prepare melts of two different drugs (i.e. Meloxicam and Diclofenac Sodium) with three SEs having wide range of HLB values $(1-16)$. Their results showed that Meloxicam release rate was increased by the presence of SEs having high HLB compared to plain powder, while, no change in the dissolution rate of Diclofinac Sodium was observed. On the other hand, low HLB values slowed the release rates for both drugs (Szüts et al., 2008). These results revealed that SDs prepared by the same SE can behave differently according to the physicochemical property of each drug. Thus, to be able to understand and estimate the pattern of drug release, it is necessary to evaluate the material properties, 
as well as the possible interactions between the drug and the carrier. Also, the physicochemical properties of drugs might give different performances with the same carrier.

\section{Stability Results:}

No information available in literature regarding the stability of IBU/SDs prepared by HME using SEs as an extrudable carrier. Thus, for final judgment of product selection prior to in vivo testing, stability of IBU/SE® WE15 preparations was carried -out for full investigation of the impact of different storage conditions on drug release using a sensitive and well-established in vitro release method. As the system stability will be anticipated to be changed due to physical transformation of drug from the amorphous to the crystalline structure.

\section{Chemical Stability by HPLC:}

Results showed no changes in color and / or appearance of the prepared formulae observed upon storage. The content of different IBU/SE ${ }^{\circledR}$ WE15 was investigated by HPLC and results showed that the drug content in all stored samples ranged between 99.01 and $103.04 \%$, which indicated that IBU was chemically stable with no trace of degradation or weight loss during the whole period of storage. Each formulation demonstrated uniform drug content with relative standard deviation ranging between 0.5 and $3.86 \%$ for samples stored for 6 months (at $40{ }^{\circ} \mathrm{C}$ and $75 \% \mathrm{RH}$ ) and 12 months at room temperature, which indicated excellent content uniformity with high chemical stability.

\section{In vitro release study for stored samples}

The comparative release profiles of stored samples were compared with initial data of freshly prepared ones by employing the similarity factor $\left(f_{2}\right)$, and the results were summarized in Table 1 and Figure 2. For samples stored for 6 months at $40{ }^{\circ} \mathrm{C} / 75 \%$ RH; Figure 2 and Table 1 showed that the percentage of IBU released after 8 hours prepared by physical mixture (i.e. PM-1 \& PM-2) and fusion method (i.e. FM-1 \& FM-2) were drastically and significantly decreased, as depicted by $f 2$ values (i.e. $f 2<50$ ). This decrease might be due to recrystallization of IBU during storage or some physical changes which might take place in SEs. On the other hand, percent IBU released from hot melt extrudates behaved differently. Where a considerable increase in release rate was observed with high IBU content (HME-1), while HME-2 $\left(30 \%\right.$ w/w IBU) stored for 6 months at $40{ }^{\circ} \mathrm{C} / 75 \%$ RH showed a decrease in IBU release rate as shown in Table 1 and Figure 2. All the tested samples were found to be unstable upon storage for 6 months at $40{ }^{\circ} \mathrm{C} / 75 \% \mathrm{RH}$ as depicted by similarity factor $(f 2$ values $<50$; cf. Table 1 ).

On the other hand, HME samples subjected to long term stability study (12 months) at room temperature revealed that only formula (HME-2) was stable as depicted by the dissolution similarity factor $(f 2$ value $=50$; cf. Table 1$)$. These results might be due to the presence of high SEs content in this formula (i.e.70\% w/w SE ${ }^{\circledR}$ WE15 in HME-2) which prolonged the system stability at room temperature.

The current results clearly confirmed the superiority of HME for preparation of IBU / SDs over other conventional methods with respect to its sustained-release properties and the stability of the final product. Also, these results highlight the need of elaborative work for studying the performance and stability of different SDs of IBU / SE® WE15 prepared by HME technique. To understand the possible reasons for the changes observed before and after storage, DSC and XRD were carried-out.

Table 1. Effect of different Storage Conditions on the Cumulative Release \% (Q 8 hours) of IBU from different samples

Cumulative IBU Release \% (Q 8 hours)

\begin{tabular}{llllllll}
\cline { 2 - 4 } Storage Conditions & PM-1 & PM-2 & FM-1 & FM-2 & HME-1 & HME-2
\end{tabular}

\begin{tabular}{|c|c|c|c|c|c|c|}
\hline Fresh & $92.23( \pm 3.96)$ & $99.83( \pm 1.18)$ & $99.28( \pm 2.96)$ & $91.48( \pm 5.25)$ & $64.65( \pm 0.12)$ & $47.09( \pm 2.98)$ \\
\hline *6 months & $65.27( \pm 4.98)$ & $69.13( \pm 4.95)$ & $73.80( \pm 1.05)$ & $58.90( \pm 2.59)$ & $99.98( \pm 1.73)$ & $24.72( \pm 1.73)$ \\
\hline Similarity Factor $\left(f_{2}\right)$ & 35 & 22 & 27 & 43 & 30 & 43 \\
\hline Similarity Factor $\left(f_{2}\right)$ & NA & NA & NA & NA & 38 & 50 \\
\hline
\end{tabular}

*6 months $\left(40{ }^{\circ} \mathrm{C} / 75 \% \mathrm{RH}\right)$

**12 months at Room Temperature.

ND: Not done.

NA: Not applicable. 


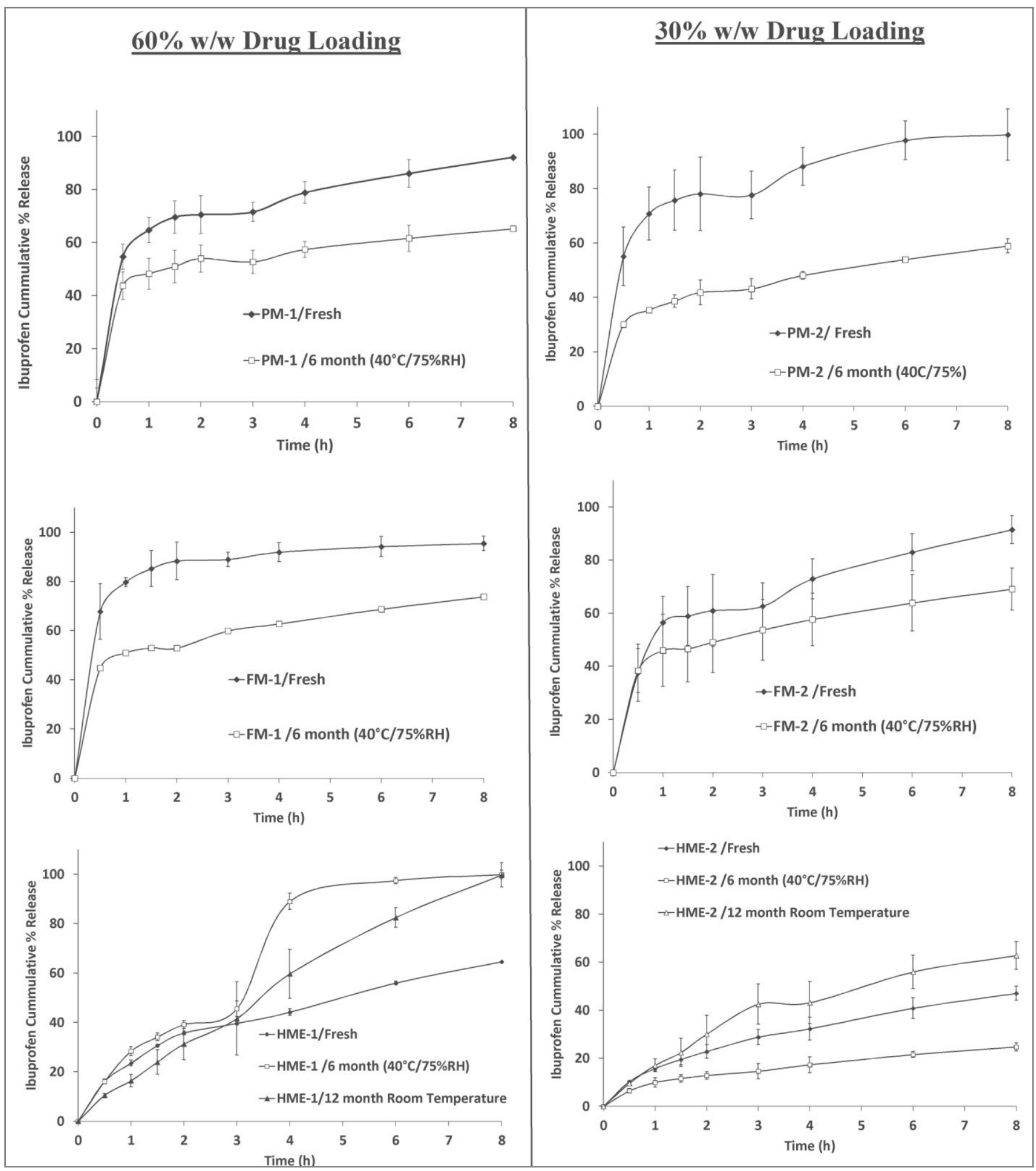

Fig. 2: Effect of different storage conditions on the release profiles of IBU/Sucroester ${ }^{\circledR}$ WE15 from SDs prepared by fusion method (FM) and hot melt extrusion (HME) compared with physical mixture (PM) (Mean $\pm \mathrm{SD}, n=3)$. 

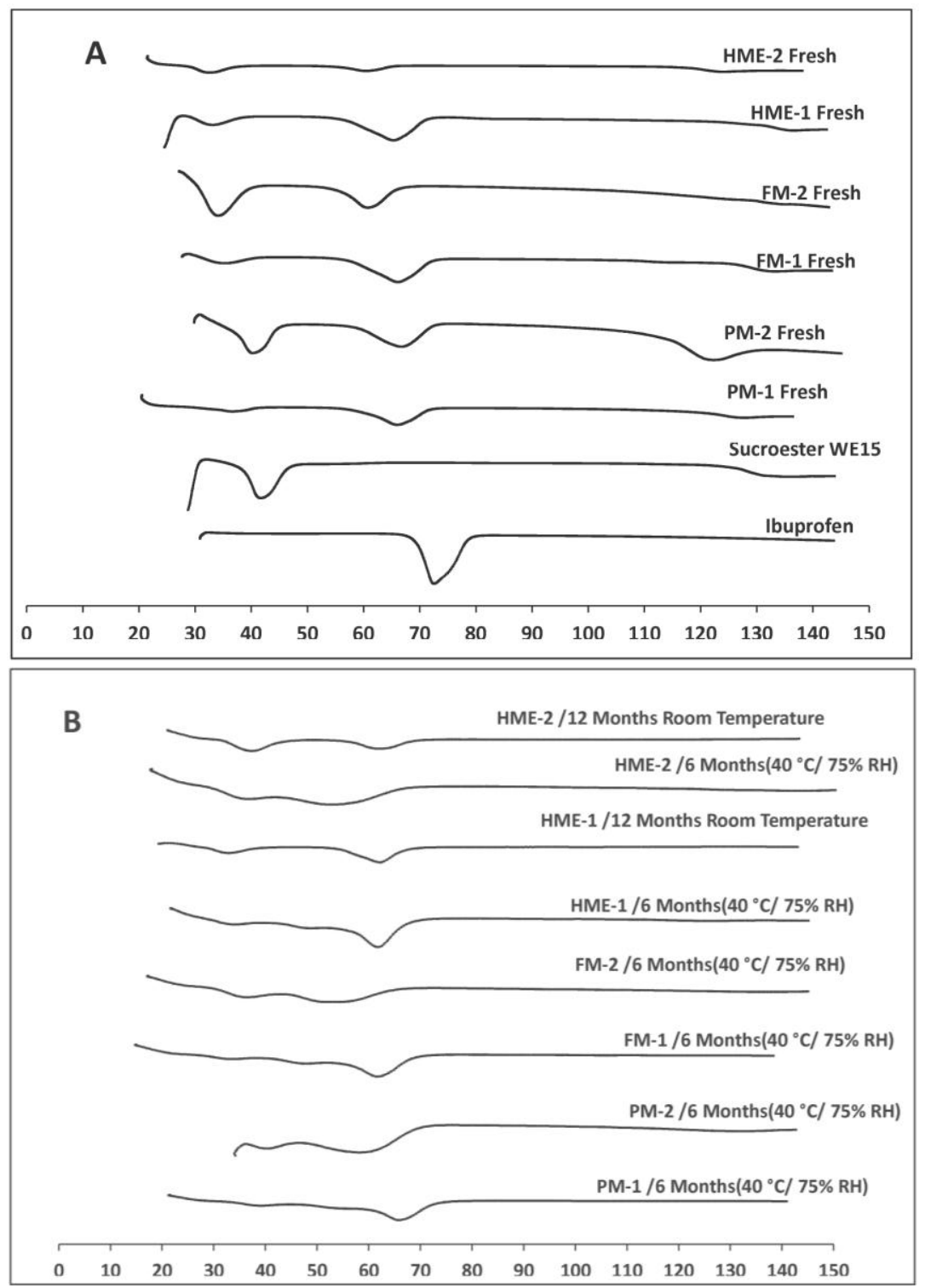

Fig. 3: DSC thermograms of IBU and Sucroester ${ }^{\circledR}$ WE15 in pure forms, PM and SDs: (A) Fresh samples; (B) Stored samples.

\section{DSC}

DSC studies of pure IBU, pure $\mathrm{SE}^{\circledR} \mathrm{WE} 15$, the PM and SDs were conducted to investigate the crystallinity and/ or drugcarrier interaction and the results were shown in Figure 3 and Table 2. The DSC thermograms showed pure crystalline IBU with a single, sharp endothermic peak at $74.15{ }^{\circ} \mathrm{C}$ which represent the melting of the drug with an enthalpy $(\Delta \mathrm{H})$ of $-88.53 \mathrm{~J} / \mathrm{g}$, while, the endothermic peaks of fresh samples ranged from 63.91 to $71.17^{\circ} \mathrm{C}$ (Table 2). The DSC thermogram of pure SE®WE15 showed an endothermic peak at $42.62{ }^{\circ} \mathrm{C}$ with enthalpy $(\Delta \mathrm{H})$ of $39.61 \mathrm{~J} / \mathrm{g}$, while the endothermic peaks of fresh samples ranged from 35.31 to $41.30^{\circ} \mathrm{C}$. As expectedly, the enthalpy values for both IBU and SE ${ }^{\circledR}$ WE15 decreased with decreasing their contents in the fresh samples. For example, PM-1, FM-1 and HME-1 (containing $60 \%$ IBU w/w), showed higher enthalpy values compared to PM-2, FM-2 and HME-2 which contain
$30 \%$ IBU w/w (Table 2, Figure 3A). Also, the same behavior was recorded in case of $\mathrm{SE}^{\circledR}$ WE15. The results obtained from the DSC thermograms of fresh samples could be correlated with the in vitro dissolution results. In case of SDs prepared by fusion method (FM-1 \& FM-2) and hot melt extrusion (HME-1 \& HME2);increasing SE ${ }^{\circledR}$ WE15 content in SDs (as in FM-2 and HME-2) led to a subsequent increase in its enthalpy (Table 2) resulting in a decrease in the amount of IBU released (Table 1). On the other hand, increasing IBU content in SDs (as in FM-1 and HME-1) led to a subsequent increase in the enthalpy of IBU (Table 2) and a simultaneous increase in the amount of IBU released (Table 1). All the samples stored under stress conditions for 6 months showed considerable reduction of the enthalpy $(\Delta \mathrm{H})$ values for $\mathrm{SE}^{\circledR} \mathrm{WE15}$; as depicted in Table 2. On the other hand, the changes of the enthalpy values for IBU did not show the same straight forward decrease pattern as that recorded with $\mathrm{SE}^{\circledR} \mathrm{WE} 15$. 
Table 2: DSC data of fresh and stored samples.

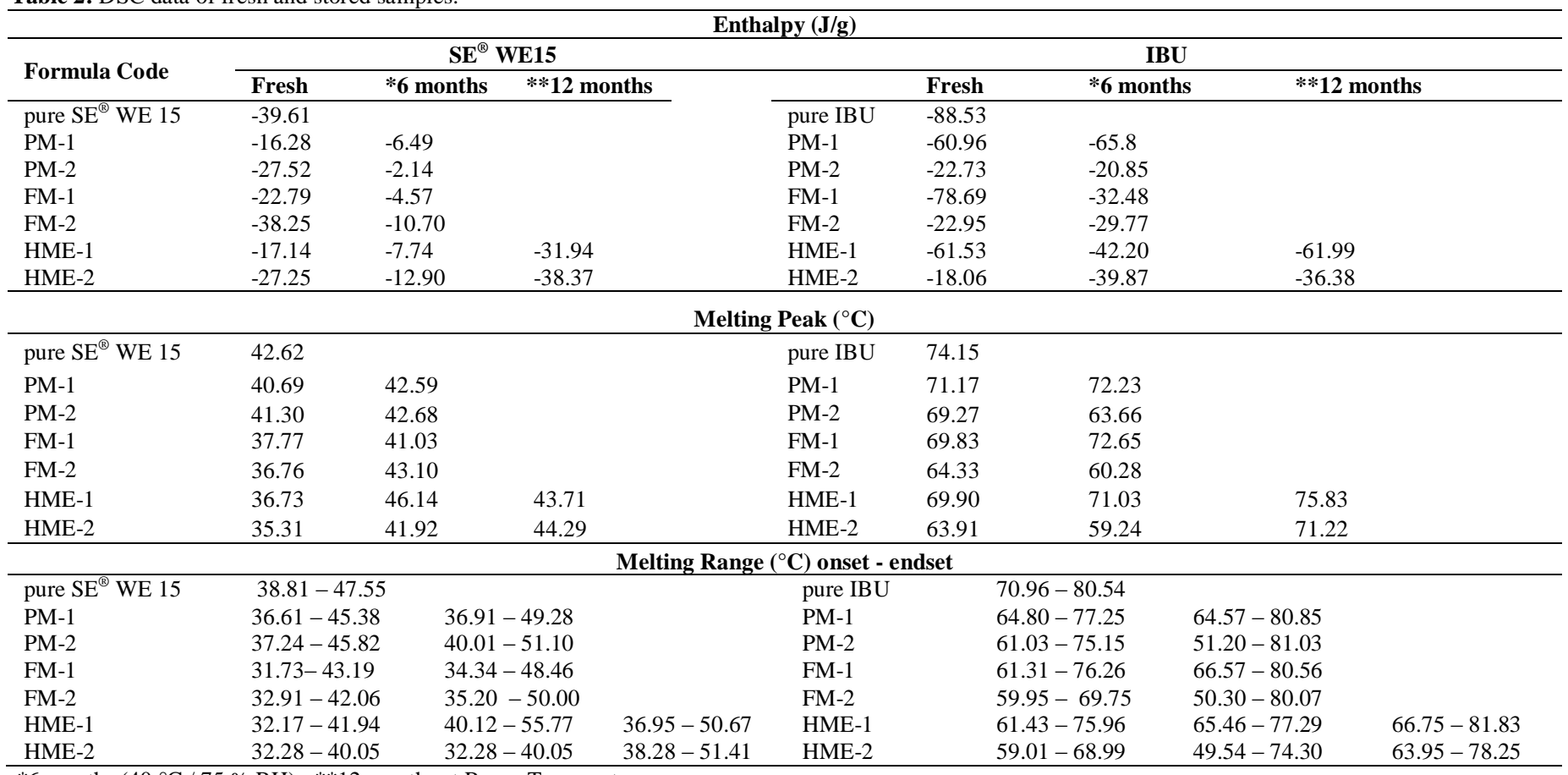

$* 6$ months $\left(40{ }^{\circ} \mathrm{C} / 75 \% \mathrm{RH}\right) ; * * 12$ months at Room Temperature.

Table 3: XRD data of fresh and stored samples.

\begin{tabular}{|c|c|c|c|c|c|c|c|}
\hline \multicolumn{8}{|c|}{ Counts } \\
\hline \multirow{2}{*}{ Formula Code } & \multicolumn{3}{|c|}{ SE $^{\circledR}$ WE15 } & \multicolumn{4}{|l|}{ IBU } \\
\hline & Fresh & *6 months & $* * 12$ months & & Fresh & *6 months & **12 months \\
\hline pure $\mathrm{SE}^{\circledR} \mathrm{WE} 15$ & 644.9591 & & & pure IBU & 2428.4200 & & \\
\hline PM-1 & 465.5429 & 404.8343 & & PM-1 & 1098.7638 & 1288.9808 & \\
\hline PM-2 & 873.5090 & 607.7043 & & PM-2 & 679.7487 & 557.0254 & \\
\hline FM-1 & 509.1560 & 419.0762 & & FM-1 & 1383.9128 & 1136.5184 & \\
\hline FM-2 & 783.6898 & 608.0393 & & FM-2 & 682.6544 & 610.1858 & \\
\hline HME-1 & 462.0656 & 175.9885 & 382.8305 & HME-1 & 1084.2043 & 1191.7921 & 1058.2062 \\
\hline HME-2 & 746.4484 & 445.7935 & 601.0246 & HME-2 & 682.7927 & 517.7523 & 621.1304 \\
\hline \multicolumn{8}{|c|}{$2 \theta\left({ }^{\circ}\right)$} \\
\hline pure $\mathrm{SE}^{\circledR} \mathrm{WE} 15$ & 21.1611 & & & pure IBU & 16.5591 & & \\
\hline PM-1 & 21.3431 & 21.3671 & & PM-1 & 16.5071 & 16.5051 & \\
\hline PM-2 & 21.3431 & 21.4191 & & PM-2 & 16.5591 & 16.5571 & \\
\hline FM-1 & 21.2651 & 21.5231 & & FM-1 & 16.4551 & 16.6091 & \\
\hline FM-2 & 21.3431 & 21.4711 & & FM-2 & 16.4811 & 16.5831 & \\
\hline HME-1 & 21.2911 & 21.1591 & 21.3149 & HME-1 & 16.5071 & 16.5831 & 16.5569 \\
\hline HME-2 & 21.4211 & 21.4191 & 21.4709 & HME-2 & 16.6111 & 16.5571 & 16.6349 \\
\hline
\end{tabular}

*6 months $\left(40{ }^{\circ} \mathrm{C} / 75 \% \mathrm{RH}\right), * * 12$ months at Room Temperature.

Where, some samples showed reduced enthalpy values for IBU (PM-2, FM-1 \& HME-1), while the rest of the samples showed the opposite behavior. Table 2 showed increased enthalpy values for both $\mathrm{SE}^{\circledR} \mathrm{WE} 15$ and IBU for HME samples (i.e. HME-1 and HME-2) stored for 12 months at room temperature, in comparison to fresh ones. Table 2 showed that the largest differences in melting range $\left({ }^{\circ} \mathrm{C}\right)$ (i.e. onset-endset) were recorded in samples containing higher content of $\mathrm{SE}^{\circledR} \mathrm{WE} 15$ (i.e. PM-2, FM-2 \& HME-2) and stored under stress conditions for 6 months. The endothermic peaks of IBU and $\mathrm{SE}^{\circledR} \mathrm{WE} 15$ in these samples lost their sharpness and distinctive appearances (Figure 3B).

This might be due to drug inclusion complexation between the two components and/or incorporation of IBU between parts of the crystal lattice of the carrier, leading to certain physical changes and a probable drug / carrier interaction.
This wider melting range difference observed in samples stored under stress conditions might be due to the changes occurring in the crystallinity of SE ${ }^{\circledR} \mathrm{WE} 15$ at elevated temperature $\left(40^{\circ} \mathrm{C}\right)$ and humidity $(75 \%)$.

This was proved by the remarkable decrease in the amount of IBU released in all samples stored under stress conditions for 6 months (Table 1).

\section{XRD}

Diffractograms of pure drug, carrier, and the prepared formulae were shown in Figure 4 and Table 3 . There were several distinctive peaks for IBU seen at $6.047^{\circ}, 12.105^{\circ}, 16.515^{\circ}$ (the major one), $17.549^{\circ}, 20.06^{\circ}, 22.633^{\circ}$ and $24.97^{\circ}$ at angle of diffraction $(2 \theta)$, which confirmed the crystalline nature of the drug. 


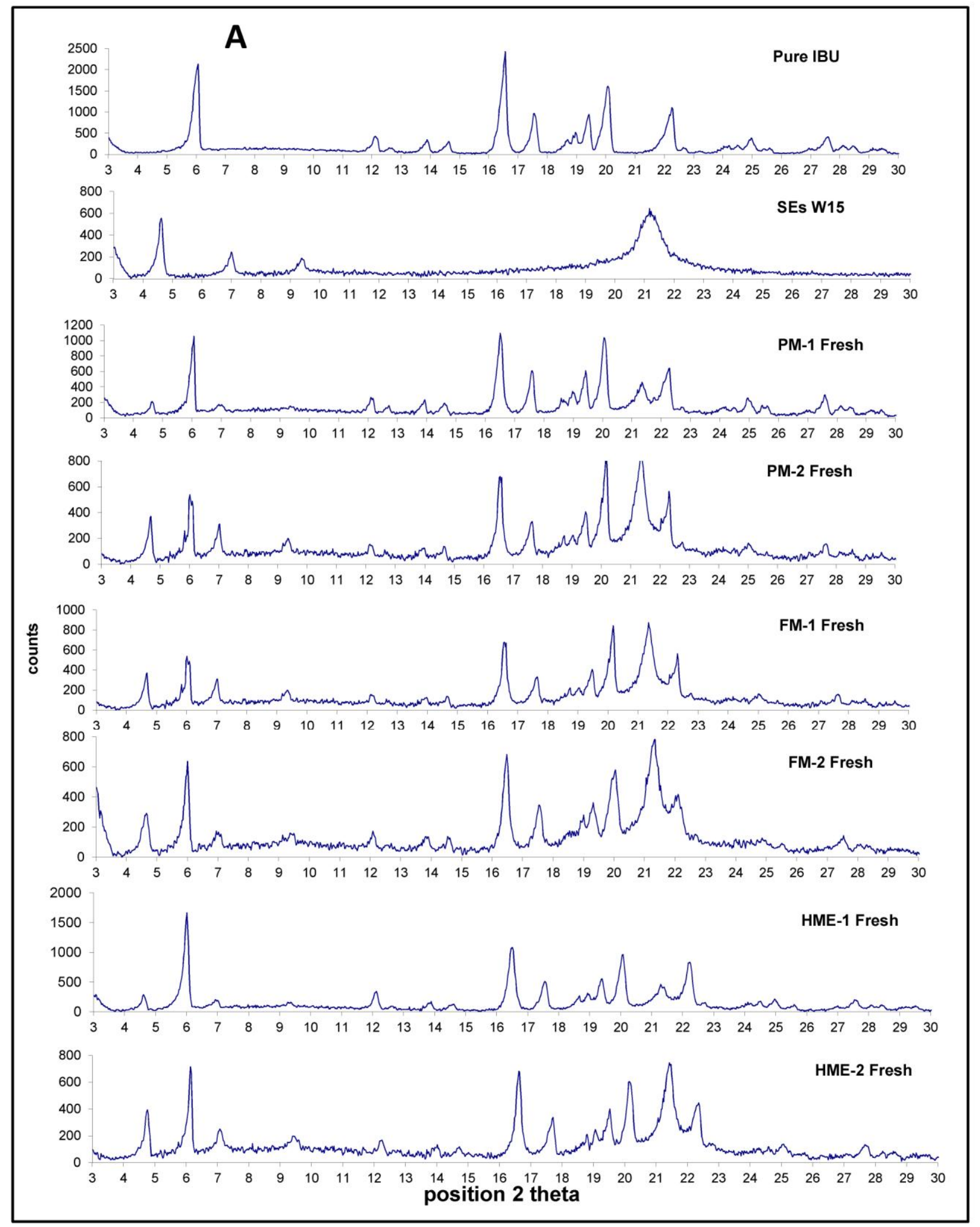

Fig. 4: XRD patterns of pure IBU, pure Sucroester ${ }^{\circledR}$ WE15, PM and SDs as a function of storage conditions (A) Fresh samples; (B) Stored samples. 


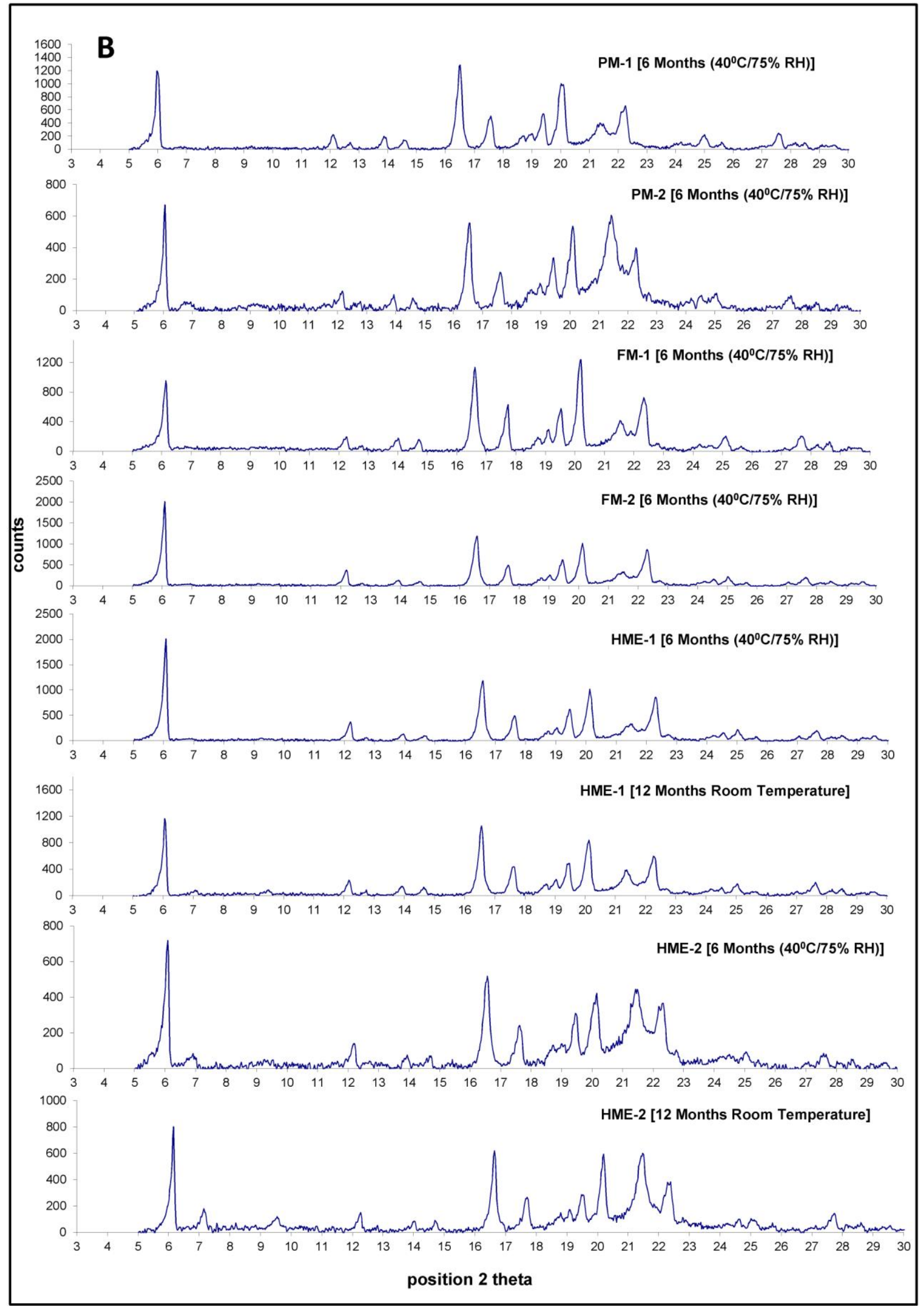

Fig. 4: XRD patterns of pure IBU, pure Sucroester ${ }^{\circledR}$ WE15, PM and SDs as a function of storage conditions (A) Fresh samples; (B) Stored samples. 
The X-ray measurements showed, that the $\mathrm{SE}^{\circledR} \mathrm{WE} 15$ displayed only one peak, at position $\left(2 \theta=21.16^{\circ}\right)$. There were also some peaks at small angles in different positions, which are characteristic of the fatty acids contained in the SEs. It can be concluded, that SEs $($ HLB $=15)$ are semi-crystalline materials, with crystalline and amorphous regions (Szüts et al., 2008).

The positions of the peaks of all samples and their intensities are listed in Table 3 and plotted in Figure 4. We have selected the major distinctive peaks of IBU and $\mathrm{SE}^{\circledR} \mathrm{WE} 15$ at $16.515(2 \theta)$ and $21.16113(2 \theta)$, respectively, to analyze the changes occurring between fresh and stored samples (Figures 4A \& B), taking into consideration that the stability of this system (IBU/SE ${ }^{\circledR}$ WE15) has not been studied before.

Although, the positions of the peaks of both IBU and $\mathrm{SE}^{\circledR} \mathrm{WE} 15$ from fresh (Figure 4A) and stored samples (Figure 4B) were not changed considerably, however, their impact might have its meaning on the solid-state changes (crystalline-amorphous ratios and polymorphism) of both components (Table 3 ).

Table 3 showed that increasing the contents of either $\mathrm{SE}^{\circledR}$ WE15 (PM-2, FM-2 \& HME-2) or IBU (PM-1, FM-1 \& HME-1) in SDs led to simultaneous increase in their intensities for fresh and stored samples, and these XRD results coincide with the results observed in DSC thermograms for both components. For fresh samples containing 60\% IBU w/w (PM-1, FM-1 \& HME-1), the degree of crystallinity of IBU was decreased to about half as compared to pure drug, while it was decreased to about fifth for samples containing 30\% IBU w/w (PM-2, FM-2 \& HME-2). These characteristic decrease in IBU peak intensities suggested that more drug was dissolved in $\mathrm{SE}^{\circledR} \mathrm{WE} 15$. As, the structures of the $\mathrm{SE}^{\circledR}$ WE15 continuously change after melting and solidification, probably because polymorphs are undergoing transformation.

The DSC scans and X-ray patterns of stored samples do not display the same pictures as that for the fresh ones. In consequence of the changes in structure, IBU might partially or completely assume a crystalline form, which might sustain or enhance its dissolution rate. In this regards, our results proved that as long as the enthalpy and intensity of IBU increased, which is a sign for a higher crystalline form, one would expect a decrease in its dissolution which was observed in case of PM and FM. However, the increase in these parameters, unexpectedly, led to an increase in the amount of IBU released in case of HME samples except HME-2 stored at stress conditions for 6 month.

\section{CONCLUSION}

The stability study of $\mathrm{SE}^{\circledR} \mathrm{WE} 15$, or any other grade, was not reported till now, in spite of its importance. Without a valid, sensitive and reproducible in vitro release test, a misleading data could be obtained. This study highlights the use of $\mathrm{SE}^{\circledR} \mathrm{WE} 15$, as an extrudable carrier, in HME technique, which behave extremely different than the fusion method. HME was able to sustain the IBU release rate with good stability especially with lower drug content. Moreover, IBU was an excellent candidate for preparation of SD by HME technique due to its known plastizing effect. The recorded DSC and XRD data were good tools to understand the effect of different manufacturing techniques on the system performance for both fresh and stored samples. HME-2 containing IBU in $30 \% \mathrm{w} / \mathrm{w}$ loading ratio was a promising formula, which add a value to this advanced technique compared to fusion method. This formula deserve to be tested in vivo on healthy human volunteers.

\section{Financial support and sponsorship: Nil.}

Conflict of Interests: There are no conflicts of interest.

\section{REFERENCES}

Aharoni SM. Increased glass transition temperature in motionally constrained semicrystalline.Polymer AdvTechn, 1998; 9:169201.

Al MasumMdA,Sharmin F, Islam SMA and Reza MdS. Enhancement of solubility and dissolution characteristics of ibuprofen by solid dispersion technique. J Pharm Sci, 2012; 11(1):1-6.

Badr RM. Improvement of nifedipine bioavailability in oral drug delivery systems. PhD Thesis, Cairo University 2006.

Battu PR, Reddy MS. RP-HPLC method for simultaneous estimation of paracetamol and ibuprofen in tablets. Asian J Research Chem, 2009; 2(1):70-72.

Breitenbach J. Melt extrusion: from process to drug delivery technology. Eur J Pharm Biopharm, 2002;54:107-117.

British Pharmacopoeia 2007. British Pharmacopoeia Commission, London: The Stationary Office.

Caron V, Tajber L, Corrigan OI, Healy AM. A comparison of spray drying and milling in the production of amorphous dispersions of sulfathiazole/polyvinylpyrrolidone and sulfadimidine/ polyvinylpyrrolidone. Mol Pharm, 2011; 8:532-542.

Craig DQ. The mechanisms of drug release from solid dispersions in water-soluble polymers. Int $\mathrm{j}$ pharm, 2002; 231(2):131-144.

Dabbagh MA, Taghipour B. Investigation of solid dispersion technique in improvement of physicochemical characteristics of ibuprofen powder. Iranian J Pharm Sci, 2007; 3:69-76.

De Brabander C, Vervaet C, Fiermans L, Remon JP. Matrix mini-tablets based on starch/microcrystalline wax mixtures. Int $\mathrm{j}$ pharm, 2000; 199(2):195-203.

De Brabander C, Van den Mooter G, Vervaet C, Remon JP. Characterisation of ibuprofen as a non-traditional plasticizer of ethyl cellulose. J Pharm Sci, 2002; 91:1678-1685.

De Brabander C, Vervaet C, Remon JP. Development and evaluation of sustained release mini-matrices prepared via hot melt extrusion. J Control Release, 2003; 89(2):235-247.

Dittgen M, Fricke S, Gerecke H, Osterwald H. Hot spin mixing: a new technology to manufacture solid dispersions. Pharmazie, 1995; 50:225-226.

Emara LH, Abdelfattah FM, Taha NF, El-Ashmawy AA, Mursi NM.In vitro evaluation of ibuprofen hot-melt extruded pellets employing different designs of the flow through cell.Int J Pharm PharmSci, 2014; 6(9):192-197.

Esnaashari S, Javadzadeh Y, Batchelor HK, Conway BR. The use of microviscometry to study polymer dissolution from solid dispersion drug delivery systems. Int J Pharm, 2005; 292:227-230.

Gawai SK, Deshmane SV, Purohit RN, Biyani KR.In vivo-in vitro evaluation of solid dispersion containing ibuprofen. American Journal of Advanced Drug Delivery.2013;1:066-072.

Gong K, Viboonkiat R, Rehman IU, Buckton G, Darr JA. Formation and characterization of porous indomethacin-PVP coprecipitates prepared using solvent-free supercritical fluid processing. J Pharm Sci, 2005; 94:2583-2590. 
Guideline, ICH Harmonised Tripartite. Stability testing of new drug substances and products Q1A (R2) 2003.Current step 4 (2012). Available

at: http://www.ich.org/fileadmin/Public_Web_Site/ICH_Products/Guidelines/ Quality/Q1A_R2/Step4/Q1A_R2_Guideline.pdf

Dissolution testing of immediate release solid oral dosage forms; guidance for industry; U.S. Department of Health and Human Services, Food and Drug Administration, Center for Drug Evaluation and Research (CDER), U.S. Government Printing Office: Washington, DC, 1997. Available at: 19, 2009).

http://www.fda.gov/ cder/guidance/1713bp1.pdf (accessed Mar

Hasnain MS, Nayak AK. Solubility and dissolution enhancement of ibuprofen by solid dispersion technique using peg 6000pvp k 30 combination carrier. Bulgarian J Sci Ed, 2012; 21(1):118-132.

Higgins JD, Gilmor TP, Martellucci SA, Bruce RD, Brittain HG. Ibuprofen. In: Harry GB, ed. Academic Press, Analytical Profiles of Drug Substances and Excipients, 2001; 27:265-300.

Hong SW, Lee BS, Park SJ, Jeon HR, Moon KY, Kang MH, Park SH, Choi SU, Song WH, Lee J, Choi YW. Solid dispersion formulations of megestrol acetate with copovidone for enhanced dissolution and oral bioavailability. Arch Pharm Res, 2011; 34:127-135.

Hülsmann STSR, Backensfeld T, Keitel S, Bodmeier R. Melt extrusion-an alternative method for enhancing the dissolution rate of $17 \beta$ estradiol hemihydrate.Eur J Pharm Biopharm, 2000; 49(3):237-242.

Islam MS, Mehjabeen K, Mustrai I, Khan F, Jalil R. Improvement of dissolution of ibuprofen and fenofibrate by poloxamer based solid dispersion. Bangladesh Pharm J, 2010; 13:54-59.

Kidokoro M, Shah NH, Malick AW, Infeld MH, McGinity JW. Properties of tablets containing granulations of ibuprofen and an acrylic copolymer prepared by thermal processes. Pharm Dev Technol, 2001; 6:263-275.

Maniruzzaman M, Boateng JS, Snowden MJ, Douroumis D. A review of hot-melt extrusion: process technology to pharmaceutical products. IntSch Res Notices, 2012: 1-9.

Moore JW, Flanner HH. Mathematical comparison of dissolution profiles. Pharm Technol, 1996; 20(6):64-74.

Newa M, Bhandaria KH, Li DX, Kwon TH, Kim J-A, Yoo B-K, Woo J-S, Lyoo WS, Yong C-S, Choi H-G. Preparation, characterization and in vivo evaluation of ibuprofen binary solid dispersions with Poloxamer 188.Int J Pharm, 2007; 343:228-237.

Newa M, Bhandaria KH, Li DX, Kim JO, Yoo DS, Kim J-A, Ypp B-K, Woo J-S, Choi H-G, Yong C-S. Enhanced dissolution of ibuprofen using solid dispersion with polyethylene glycol 4000.Biol Pharm Bull, 2008a; 31:939-945.

Newa M, Bhandaria KH, Li DX, Sung JH, Kim JO, Yoo B-K, Woo J-S, Choi H-G, Yong CS. Enhanced dissolution of ibuprofen using solid dispersion with polyethylene glycol 20000. Drug Dev Ind Pharm, 2008b; 34:1013-1021.

Newa M, Bhandaria KH, Oh DH, Kim YR, Sung JH, Kim JO, Woo J-S, Choi H-G, Yong CS. Enhanced dissolution of ibuprofen using solid dispersion with Poloxomer 407. Arch Pharm Res, 2008c; 31:14971507.

Ofokansi KC, Kenechukwu FC, Ezugwu RO, Attama AA. Improved dissolution and anti-inflammatory activity of ibuprofenpolyethylene glycol 8000 solid dispersion systems.Int J Pharm Investig. 2016; 6(3):139-147.

Özgüney I, Shuwisitkul D, Bodmeier R. Development and characterization of extended release Kollidon ${ }^{\circ}$ SR mini-matrices prepared by hot-melt extrusion.Eur J Pharm Biopharm, 2009; 73(1):140-145.
Park YJ, Kwon R, Quan QZ, Oh DH, Kin JO, Hwong MR, Koo YB, Woo J-S, Yong C-S, Choi H-G. Development of novel ibuprofenloaded solid dispersion with improved bioavailability using aqueous solution. Arch Pharm Res, 2009; 32:757-772.

Sekikawa H, Fukuda N, Takada M, Ohtani K, Arita T, Nakano M. Dissolution behavior and gastrointestinal absorption of dicumarol from solid dispersion systems of dicumarolpolyvinylpyrrolidone and dicumarolbeta-cyclodextrin. Chem Pharm Bull, 1983; 31:1350-1356.

Serajuddin, Abu. Solid dispersion of poorly water-soluble drugs: early promises, subsequent problems, and recent breakthroughs. J pharm sci, 1999; 88(10):1058-1066.

Shahrin N and Huq A. Development of ibuprofen loaded solid dispersion with improved dissolution using tween 80 \& span 80 . Int $\mathrm{J}$ Pharma Life Sci. 2012; 1(1):1-7.

Stanković M, de Waard H, Steendam R, Hiemstra C, Zuidema J, Frijlink HW, Hinrichs, WLJ. Low temperature extruded implants based on novel hydrophilic multiblock copolymer for long-term protein delivery. Eur J Pharm Sci, 2013; 49(4),578-587.

Szüts A, Makai Z, Rajkó R, Szabó-Révész P. Study of the effects of drugs on the structures of sucrose esters and the effects of solidstate interactions on drug release. J pharm biomed anal, 2008; 48(4):11361142 .

Van den Mooter G, Weuts I, De Ridder T, Blaton N. Evaluation of Inutec SP1 as a new carrier in the formulation of solid dispersions for poorly soluble drugs.Int j pharm, 2006; 316(1):1-6.

Verhoeven E, Vervaet C, Remon JP. Xanthan gum to tailor drug release of sustained-release ethylcellulose mini-matrices prepared via hotmelt extrusion: in vitro and in vivo evaluation. Eur $\mathrm{j}$ pharm biopharm, 2006; 63(3):320-330.

Vilhelmsen $\mathrm{T}$, Eliasen $\mathrm{H}$, Schæfer $\mathrm{T}$. Effect of a melt agglomeration process on agglomerates containing solid dispersions. Int $j$ pharm, 2005; 303(1):132-142.

Won DH, Kim MS, Lee S, Park JS, Hwang SJ. Improved physicochemical characteristics of felodipine solid dispersion particles by supercritical anti-solvent precipitation process.Int $\mathrm{j}$ pharm, 2005; 301(1):199-208

$\mathrm{Xu}$ L, Li SM, Sunada H. Preparation and evaluation of ibuprofen solid dispersion systems with kollidon particles using a pulse combustion dryer system. Chem Pharm Bull, 2007; 55:1545-1550.

Zhang F, McGinity JW. Properties of hot-melt extruded theophylline tablets containing poly (vinyl acetate). Drug devind pharm, 2000; 26(9):931-942.

\section{How to cite this article:}

Emara LH, Abdelfattah FM, Taha NF. Hot melt extrusion method for preparation of ibuprofen/sucroester WE15 solid dispersions: evaluation and stability assessment. J App Pharm Sci, 2017; 7 (08): 156-167. 